\title{
Erratum to: Molecular evolution and functional specialization of chalcone synthase superfamily from Phalaenopsis Orchid
}

\author{
Ying-Ying Han · Feng Ming • Wei Wang • \\ Jing-Wen Wang $\cdot$ Ming-Ming Ye $\cdot$ Da-Leng Shen
}

Published online: 8 October 2009

(C) Springer Science+Business Media B.V. 2009

Erratum to: Genetica (2006) 128:429-438

DOI: $10.1007 / s 10709-006-7668-x$

Figure 4 in the original publication was replaced incorrectly with the image of Fig. 3.

The corrected Fig. 4 should be read as:

The online version of the original article can be found under doi:10.1007/s10709-006-7668-x.

Y.-Y. Han · F. Ming $(\bowtie) \cdot$ W. Wang $\cdot$ J.-W. Wang

M.-M. Ye · D.-L. Shen

Institute of Genetics, State Key Laboratory of Genetic

Engineering, Research Centre of Gene Diversity and Designed

Agriculture, Ministry of Education Key Laboratory for

Biodiversity Science and Ecological Engineering, School of Life

Science, Fudan University, Handan road 220, 200433 Shanghai,

China

e-mail: fming@fudan.edu.cn 
Fig. 4 Expression of different chs genes in various organs and stages of development in

Phalaenopsis hybrid (in mauve color) by RT-PCR. The amounts of actin transcripts were used as internal control. Primers used for the amplification are positioned at the nonconservative regions

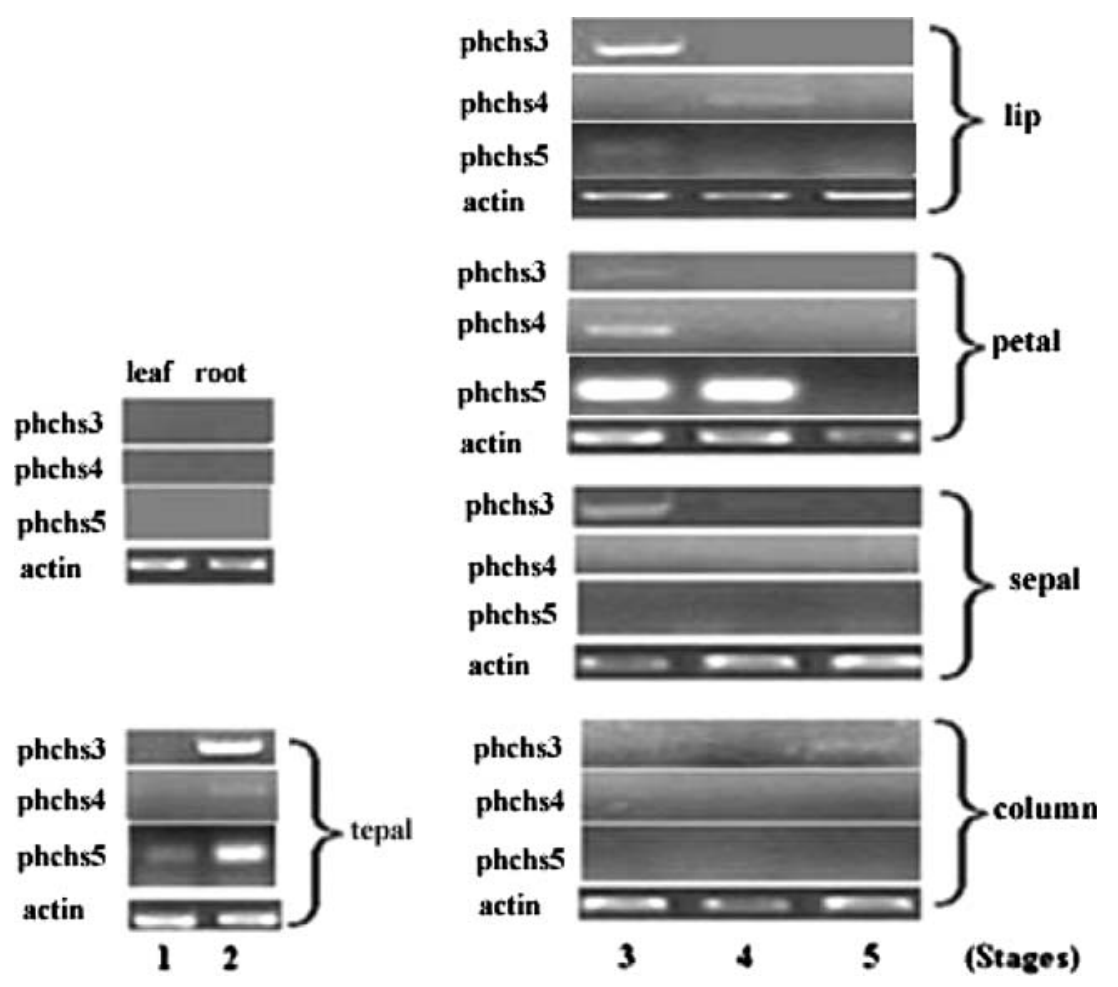

